\title{
The Political Science Research and Teaching List
}

\author{
William J. Ball, Trenton State College
}

The Political Science Research and Teaching list (PSRT-L) is a moderated electronic discussion list on the Bitnet computer network (part of the internet). It deals with issues of interest to professional political scientists, both researchers and teachers. After three years in operation PSRT-L has grown to about 750 participants in 28 countries.

Submissions from all sub-fields of political science as well as related disciplines are encouraged. A subscriber to the list can submit questions or comments merely by sending an electronic mail note to PSRT-L AT MIZZOU1.MISSOURI.EDU. These notes are collected into digests which are then periodically re-posted to all subscribers. There are no costs associated with being a subscriber to PSRT-L once one has access to the network.
PSRT-L is not intended to serve as a public forum for debate over current issues in politics as other lists fill that niche. Rather it is intended to provide an opportunity for political scientists to ask for advice, to present their ideas and ongoing research for discussion, to consider the directions in which the discipline is advancing, and to encourage the dissemination of new concepts in research and teaching. In addition, the list editors regularly post anouncements of job openings, other more specialized discussion lists, and upcoming conferences. A series of archival files are available to the subscriber of PSRT-L.

PSRT-L also publishes and archives The Law and Politics Book Review, edited by Herbert Jacob. Although the Review is a regular feature of the discussion list, PSRT-L tries to be as general as possible in its coverage of political science. An increasing number of specialized political science lists are springing up and PSRT-L does not try to duplicate their efforts.

You are invited to subscribe to PSRT-L by sending an electronic mail request to LISTSERV AT MIZZOU1.MISSOURI.EDU, including your name. The body of the note should read:

\section{SUBSCRIBE PSRT-L your name}

You are also invited to submit comments and questions to the list by sending a note to PSRT-L AT MIZZOU1.MISSOURI.EDU. If you have difficulty getting subscribed feel free to send a note to Bill Ball at the following address: POLPSRT AT MIZZOU1.MISSOURI.EDU.

\section{Political Science and U.S. Policy Toward China*}

\author{
Tao Wu, Arizona State University \\ Yang Zhong, The University of Tennessee
}

\author{
Recently, the strain between political \\ science research and public policy \\ practice has drawn increasing atten- \\ tion among political scientists. Most \\ of the discussions on this topic have \\ focused on three issues. First, the \\ gap $^{1}$ is becoming wider between \\ political scientists on the one hand \\ and public policy analysts (Sabatier \\ 1992) and policy practitioners \\ (Herspring 1992) on the other. \\ Second, political science research has \\ been divorced from public policy \\ studies and the practice of politics \\ (Moe 1991; Sundquist 1991; Kam- \\ marck 1990). Third, political scien- \\ tists have a small role to play in \\ making public policy (Sundquist \\ 1991; Maxwell 1992). \\ Using the results of a survey we
}

recently conducted among political scientists specializing in Chinese politics at American universities, this article examines one segment of political scientists-professors teaching Chinese politics-with regard to tensions between political science research and public policy practice, and looks for solutions to narrow the gap between the two.

The strain between political science and public policy is a broad issue. Our paper only focuses on tensions between political scientists specializing in international relations and comparative politics and career bureaucrats in the area of foreign policy. Discrepancies have long existed between career bureaucrats who practice foreign affairs and political scientists who study the conceptual and theoretical aspects of international affairs. ${ }^{2}$ The former tend to view abstract conceptualization as "academic nonsense" that has little policy relevance, while the latter downplay the knowledge that practitioners gain from their daily execution of foreign policy because it contributes little to theory building (Herspring 1992, 554). To maintain their commitment to scientific research and their image as value-free researchers, the dominant view within the discipline of political science is that political scientists should not get involved in politics nor use their expertise to influence political behavior.

Now, many people are becoming 
more concerned about this gap because it is getting wider. Political scientists are responsible for the gap on at least three counts.

The first is their view toward theory and practice. Because of their predominant concern about theoretical development and model construction, political scientists often neglect the details of specific policy issues.

The second is the acultural approach taken by many political scientists who study international relations and foreign policy. Their propensity for theory building leads them to deemphasize the culture and history of the countries they study. In positive terms, such an approach can be justified for a neutral testing of theories and concepts. In negative terms, such an approach can be interpreted as "since we don't know the languages or the cultural backgrounds of the countries we study, let us find a conceptual framework that will do the work for us"

(Herspring 1992, 555). Consequently, their theoretical models are often incorrect because of an insufficient understanding of the subject countries.

The third is the stereotype of policy makers and public servants held by people in academia. For example, military officers are often perceived as right-wingers and Foreign Service officers as conservatives (Herspring 1992, 556). As a result, these people are thought to be poorly qualified to do scientific research because of their political bias.

\section{The Community of China Scholars}

Before discussing our survey, we need to look at some of the general features of China specialists in the academic community. ${ }^{3}$ Based upon our literature research, we assume that this group of political scientists does not quite fit the prevailing description regarding the tension between political scientists and policy practitioners.

First of all, China scholars are known for their emphasis on cultural factors in their research. We believe that this inclination is shared by China specialists in the State Depart- ment, private research institutions, and consulting firms. A view held by many Sinologists is that "China is China is China"' (Oksenberg 1970, iv) and "China is not just another nation state in the family of nations" (Pye 1990, 58). The emphasis on the uniqueness of China among China scholars has led to the accusation that they are overly sympathetic with and tolerant of the "Chinese way of doing things" even though, in reality, China scholars frequently criticize Chinese society and government.

Second, this is not a group of scholars that has been ignored by U.S. policy makers. China scholars are useful to foreign policy makers

\section{'Since we don't know the} languages or the cultural backgrounds of the countries we study, let us find a conceptual framework that will do the work for us."

because they possess special knowledge about an important country that is significantly different from the West, and about which the general public as well as politicians know very little. Because of their small number and the unique knowledge they possess, China scholars have been treated as an asset by U.S. policy makers. As Myers and Metzger (1980) pointed out,

The U.S. [foreign] policy is not shaped only by the weighing of strategic and economic variables in the Oval Office. It is also shaped by the various sectors of American public opinion as perceived in the Oval Office. Moreover, in the case of China policy, the more informed or intellectual sector seems particularly influential in Washington (p. 114).

Third, China scholars have a tradition of voicing their concerns and being involved in the formation of U.S. policy toward China. After the purge of the China watchers in the State Department in the early 1950s, China scholars in American universities became one of the few voices to advocate establishing contacts with the People's Republic of China. Since the 1950s, there have been two main paradigms in the study of Chinese politics: the "modernizing communist regime" paradigm and the "revolutionary socialist paradigm" (Mosher 1990). Advocates of both paradigms criticized the U.S. policy of isolating the People's Republic before the 1970s and urged the United States to change this policy.

Because the mood of the American public was characterized by strong anti-communist sentiment, American China scholars did not have much influence beyond the academic community until the early 1970 s when they were granted opportunities by Richard Nixon's visit to China and his new China policy of constructive engagement. It seems that Nixon's perception of the People's Republic of China was close to that of many China scholars. For example, Nixon was fascinated by Chinese history and culture and perceived the Chinese communists as distinctively different from the Russian communists. The main motive of Nixon's new China policy was, of course, the strategic value of China in the U.S.Soviet global rivalry. Nixon's views about China and U.S.-China relations were by and large shared by his successors: Gerald Ford, Jimmy Carter, Ronald Reagan, and George Bush.

Due to agreement in policy preference between policy makers and China scholars, some China specialists in academic community gained prominence and were brought into the policy arena in the 1970s and 1980 s. For example, China specialists such as Allen Whiting and Michel Oksenberg served at one time or another as advisors to the White House and the State Department. China scholars were often called to Capitol Hill to testify on Chinarelated affairs. There is no doubt that China scholars were actively involved in building the bipartisan consensus on U.S. relations with China in the 1970s and the 1980s.

\section{Our Survey and Findings}

Our survey of political scientists teaching Chinese politics had three 
goals. First, we wanted to know the general mood of China scholars and their perceptions about China in the post-Cold War world. Second, we intended to find out their opinions on current U.S. China policy which is likely to change under the Clinton administration. Third, we hoped that our findings could suggest some solutions to narrow the gap between political science and public policy.

The survey took the form of a mail questionnaire. It was conducted in a two-month period, between October 28 and December 24, 1992. The target population was professors teaching and studying Chinese politics in political science departments that grant post-graduate degrees. They were identified in Graduate Faculty and Programs in Political Science (APSA 1992), which lists the research and teaching specialty of all professors in political science departments of American universities that offer a graduate program. A total of 127 China specialists were identified, and a questionnaire was sent to each. The survey was confidential. The response rate approached $50 \%$, a good response for a mail questionnaire survey.

Here we will only report those findings pertaining to our concerns in this paper. First of all, we found that most of the respondents are more concerned with regional stability in Asia and U.S. economic relations with China than with human rights and political order in China. When asked to rank their policy concerns, the China scholars surveyed gave a total score of 154 to regional stability (see Table 1). U.S. economic ties with China are ranked second by this group of China watchers. Human rights and political stability came in third and fourth respectively. This finding means that the policy preferences of China specialists in the academic community are more in line with the posture of the Bush administration, which attached more strategic and economic importance to its China policy than moral and ideological values. ${ }^{4}$ Indeed, when asked to self-report their policy support, more than half of the respondents favored Bush's China policy while only about one-third of them preferred Clinton's proposed "'getting tough" policy with China ${ }^{5}$ (see Table 2).
Besides the question of general policy orientation toward China, we also tapped directly the views of China scholars on some specific policy issues involved in U.S.-China relations. Our findings show that most respondents favor a softer approach in dealing with China. Two out of three of the respondents are not supportive of using strong outside pressure to force the Chinese government to change its behavior (see Table 3 ). Nearly $80 \%$ of the respondents oppose an outright revocation of the most-favored-nation trade status for China. However, the respondents are almost evenly divided on conditioning China's most-favored-nation trade status. Moreover, most of the respondents disagree with the Bush administration's decision to sell 150 F-16 jet fighters to Taiwan. This finding is consistent with their predominant concern with stability in Asia.

We also asked for assessments of China's domestic situation and its international role. Even with the Cold War's ending, some $75 \%$ of the respondents still believe that China has an important role to play in today's world. Turning to the domestic situation in China, every one of the respondents regards the economic reforms in China since the late 1970s as a success. However, fundamental political changes in China in the near future do not seem to be promising in the eyes of the China specialists. Only $5 \%$ of the respondents predict significant political changes will occur in less than five years. Another $25 \%$ expect political changes in less than 10 years. Most of the respon-
TABLE 1

Rank Order of Policy Concerns

\begin{tabular}{lrrrrr}
\hline & \multicolumn{4}{c}{ Frequency } & \\
\cline { 2 - 5 } & 1 & 2 & 3 & 4 & Total Score \\
\hline Regional Stability & 24 & 12 & 9 & 4 & 154 \\
Sino-U.S. Economic Ties & 14 & 16 & 11 & 8 & 134 \\
Human Rights in China & 4 & 13 & 17 & 15 & 104 \\
Political Order in China & 7 & 8 & 12 & 22 & 98 \\
\hline Valid N = 49 & & & \\
Note: The total score for each policy concern was calculated according to the following equations: \\
rank $1=4$ points, rank 2 = 3 points, rank 3 = 2 points, and rank 4 = 1 point.
\end{tabular}

TABLE 2

Support for Bush or Clinton

China Policy

\begin{tabular}{lc}
\hline Favor Bush & $52.6 \%$ \\
Favor Clinton & 33.3 \\
No Opinion & 10.5 \\
Missing & 3.5 \\
& 100.0 \\
\hline
\end{tabular}

Valid $\mathrm{N}=55$

TABLE 3

Putting Pressure on China

\begin{tabular}{lccccr}
\hline & $\begin{array}{c}\text { Revoking } \\
\text { MFN }\end{array}$ & $\begin{array}{c}\text { Conditional } \\
\text { MFN }\end{array}$ & $\begin{array}{c}\text { Strong Pressure } \\
\text { for Change }\end{array}$ & $\begin{array}{c}\text { Fighter } \\
\text { Sale }\end{array}$ & $\begin{array}{r}\text { Mean } \\
\text { Score }\end{array}$ \\
\hline Strongly Agree & $3.5 \%$ & $19.3 \%$ & $5.3 \%$ & $8.8 \%$ & $9.2 \%$ \\
Agree & 12.3 & 26.3 & 17.5 & 24.6 & 20.2 \\
Disagree & 36.8 & 29.8 & 36.8 & 35.1 & 34.6 \\
Strongly Disagree & 38.6 & 21.1 & 38.6 & 22.8 & 30.3 \\
No Opinion & 3.5 & - & 1.8 & 5.3 & 3.5 \\
Missing & 5.3 & 3.5 & - & 3.5 & 4.1 \\
\hline & 100.0 & 100.0 & 100.0 & 100.0 & 100.0 \\
\hline
\end{tabular}

Total $\mathrm{N}=57$ 
dents suggest 20 years or longer.

In general, most respondents favor a cautious approach in dealing with China. What they are saying seems to be this: if things are going well on China's economic front, why rock the boat now? If China is still an important player in the post-Cold War world, why irritate her? If regime change is going to take a long time, why not be patient with China?

It is important to note that our survey findings are also congruent with policy recommendations of a couple of recent reports on U.S.China relations by American Asian experts, former diplomats, and businessmen. The first report, released in late January 1993 by a panel of top American Asian experts, recommends that the Clinton administration adopt a policy of "constructive engagement" with China.

Another report issued by the Atlantic Council and the National Committee on U.S.-China Relations also recommends against isolating China. Instead, it suggests that the U.S. resume high-level discussions with the Chinese government on issues such as China's human rights practice.

\section{Conclusion}

Since we only surveyed a homogeneous group of political scientists, i.e., China scholars in American universities, we do not intend to make sweeping generalizations about political scientists as a whole. However, we think we have learned the following from our study. First, not all political scientists have negative views about involvement in public policy. American China scholars have a tradition of voicing their views regarding the formation of U.S. China policy since the 1950 s. ${ }^{6}$

Second, many area specialists attach great importance to cultural factors in their study. Our survey shows that, as in the past, the belief of China exceptionalism is still strong among China scholars in the 1990s. In our view, the major reason that China scholars favor a cautious treatment of China is because they believe that Chinese society and politics are much more complex than they appear to be. As John K. Fairbank said, Americans should not impose their values upon China whose culture and history are significantly different from those of the United States (1992).

Third, we found that scholars are not unconcerned with policy issues in the United States and the countries they study. In our survey, $80 \%$ of the respondents claim that they follow China-related news very closely, and the rest say they do somewhat closely. We also found that most scholars have opinions on public policy issues and are willing to express them. The response rate (about 50\%) to our survey is evidence. We believe that much more

. . the major reason that China scholars favor $a$ cautious treatment of China is because they believe that Chinese society and politics are much more complex than they appear to be.

can be learned about policy preferences of China scholars from this poll than from surveying newspaper editorials and position papers.

Our findings indicate that things may not be as bad as Ronald Moe (1991) suggested: "if some were to call upon the discipline for advice and assistance, the discipline might have little to contribute and that it is unusual today to find political scientists with any experience at all in governmental institutions or affairs" (415). As Samuel Huntington pointed out some years ago, political scientists in various parts of the world have actively participated in political campaigns, societal transformation, and governmental institutional affairs. American China scholars are an example of this.

Finally, our study probably suggests the first step to narrow the gap between political science and public policy. We believe that a major reason that political scientists have played a small role in policy making is because they are rarely offered opportunities to systematically voice their views on policy matters. Political scientists have done a lot of surveys of other people, but they seldom do one of themselves. We know that opinion polls on policy matters have been taken in other professional groups such as lawyers, medical doctors, psychologists, and economists. Why can't we tap our own views on political and policy issues? Nobody will take our views seriously before we ourselves do.

We share Herspring's (1992) assumption that the majority of political scientists, specializing in foreign affairs, want to do work that both contributes to theory building and is helpful to policy makers (557). We believe that our survey, which taps the views of one group of political scientists on their policy preferences, registers a first effort in that direction.

\section{Notes}

*The authors would like to thank Jerry Duff for his helpful comments on an earlier draft of this paper.

1. The gap refers to the differences in research focus, attitudes toward theory and practice, political values in research, and involvement in decision making.

2. Foreign policy analysts in public policy institutions stand somewhere in between the two. Most of them "have an activist bent, i.e., at some point they wish to influence policy in the area(s) in which they are specialists"' (Sabatier 1991, 145). However, they are not the focus of our paper.

3. China scholars in this article refer to those who study and teach Chinese politics at American universities. Some people may wonder why this group of scholars was chosen for the study. Our survey explores the policy preferences of China scholars as compared to the current U.S. China policy. Examination of the tensions between public policy and political science is only one of our goals. Critics may say that China scholars are not representative of political scientists as a whole because their research methods tend to be traditional and policy oriented. This, we believe, is a misperception. Many area specialists, including China scholars in academic institutions, have adopted, or are familiar with, scientific methods in the study of their subject countries. Besides, their main job is not to follow current events in the countries they study or to provide policy recommendations for the U.S. government.

4. We do not have a comparable survey of those who conduct U.S. foreign policy in government agencies. We assume that the current U.S. policy toward China represents their views. However, we do not dispute that sometimes government policies do not reflect the views of career bureaucrats. 
5. We do not want to rule out the possibility that some of the China specialists are government contractors, and their government ties may have contributed to the similarities in policy preferences. However, we still believe that the policy congruence is largely because of shared perceptions about cultural as well as strategic and political factors in China studies than links to the government. We did not ask whether people have government contracts in our survey because we think that it may complicate their answers to the other questions.

6. We suspect similar situations may also exist among other area specialists in political science. We do not believe that the case of China scholars is an anomaly. Our study may encourage other area specialists to do similar studies in their area to examine the gap between political science and public policy.

\section{References}

Fairbank, John K. 1992. China: A New History. Cambridge: Harvard University Press.

Herspring, Dale R. 1992. "Practitioners and Political Scientists." PS: Political Science \& Politics 15(3): 554-58.

Huntington, Samuel. 1988. "One Soul at a Time: Political Science and Reform." American Political Science Review 82: 3-10.
Kammarck, E. C. 1990. "Political Scientists in Presidential Campaigns." PS: Political Science \& Politics 23(3): 428-29.

Leigh, Lawrence J. 1991. "Political Scientists as Expert Witnesses." PS: Political Science \& Politics 24(3): 521-23.

Maxwell, Mary. 1992. "The Gulf War and Political Science." PS: Political Science \& Politics 25(4): 693-95.

Moe, Ronald C. 1991. "Political Science and the Savings and Loan Crisis." PS: Political Science \& Politics 24(3): 451-55.

Mosher, Steven W. 1990. China Misperceived: American Illusions and Chinese Reality. New York: Basic Books.

Myers, Ramon H., and Thomas A. Metzger. 1980. "Sinological Shadows: The State of Modern China Studies in the United States." The Washington Quarterly 3: 144.

Oksenberg, Michel. 1970. A Bibliography of Secondary English Language Literature on Contemporary Chinese Politics. New York: East Asian Institute, Columbia University.

Pye, Lucian. 1990. "China: Erratic State, Frustrated Society." Foreign Affairs 69(4): 58.

Sabatier, Paul A. 1991. "Political Science and Public Policy." PS: Political Science \& Politics 24(2): 144-46.

Sundquist, James L. 1991. "Political Scientists and Public Policy Research." PS: Political Science \& Politics 24(3): 531-34.

\section{About the Authors}

Tao Wu

Tao Wu is a Ph.D. candidate in American politics at Arizona State University. $\mathrm{He}$ is completing his dissertation on "Party Reforms and the Transitions of Political Elites: 19721988' in 1994.

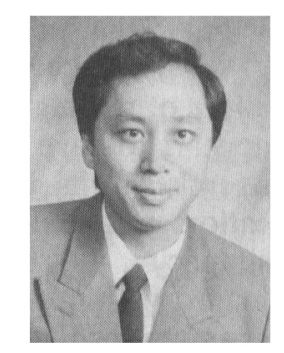

\section{Yang Zhong}

Yang Zhong is an assistant professor in the department of political science at The University of Tennessee, where he teaches Chinese and comparative politics. His publications have appeared in Studies

in Comparative Communism, Armed Forces and Society, Journal of Asian and African Affairs, and Pacific Focus.

\title{
Procrustus and the Regression Model: On the Misuse of the Regression Model
}

\author{
James P. McGregor, U.S. Information Agency
}

In The Logic of Scientific Revolutions, Thomas Kuhn (1970) described the power of prevailing paradigms to assist-or impede-progress in the sciences. A paradigm channels thinking and observation; under conditions of what Kuhn calls "normal science," it dictates what is a fact and the methods by which that fact is to be studied.

While the social sciences are not yet subject to a single paradigm, scholars tend to behave as if a paradigm prevailed, especially with respect to method. The introduction of the scientific method to mainstream social science represented a powerful advance in the study of mankind and his institutions. Unfortunately, it also brought with it potent tendencies toward scientism and considerable resistance to challenges to the methodological canon.

My argument is that one of the principal icons of social scientiststhe regression model-has been misused and, in my view, has been a major impediment to progress in political science as well as in other social sciences. I submit that the method has not only been abused by general failure to apply it properly but also that the model is not a reasonable way of looking at the world of politics.

\section{The Regression Model}

The regression model dominates empirical work in political science. Rough evidence of this can be found in a review of articles in the Ameri- can Political Science Review over the past year: almost every article that displayed findings in tabular form used some form of regression analysis-ordinary least squares, generalized least squares, probit or logit analysis. To be sure, many of these analyses were preceded by or supplemented with other methods such as simple marginals, crosstabulation or correlations-but the key method was regression.

The regression model has powerful attractions. Under the proper conditions, it can provide precisely the type of information political scientists need in their search for explanations of political phenomena. It can summarize the relationship among variables in a parsimonious and precise manner and has the additional virtues of being relatively easy to 